Open Access

\title{
Examining the control of bird flu risks among Nigerian poultry producers: implication for effectiveness of biosecurity knowledge, attitude, and practices (EBKAP)
}

\author{
Benjamin Okpukpara
}

Correspondence:

Benjamin.okpukpara@unn.edu.ng; benedozie@yahoo.com Centre for Entrepreneurship and Development Research, University of Nigeria, Nsukka, Nigeria

\begin{abstract}
This study examined socio-economic and behavioral factors affecting Nigerian poultry producers' biosecurity practices in terms of knowledge about bird flu symptoms, beliefs about safe practices, and handling products as well as perception on disease risk transmission. The study is a result of incidence of bird flu in Nigeria, which affected the livelihood of poultry producers. The study used a survey design. The choice of location and population of study (Kano, Lagos, and Anambra states) was based on bird flu disease risk map and population of small-scale poultry farmers in Nigeria. The study used both descriptive and causal analytical tools to achieve the specific objectives of the study. The major findings were that producers with higher knowledge were able to make more informed and rational assessment of true disease spread risks, KAP indices are not important in explaining the actual biosecurity decisions of the Nigerian producers. The study also found that adoption of biosecurity actions depends on flock size (which related to income), educational level of farmers, and incidence of bird flu previously in the area. In addition, smaller and poorer producers adopt fewer biosecurity actions, thus they are considered to be riskier in terms of disease transmission. The study therefore, recommended among other things a well-planned education programs to improve knowledge of bird flu symptoms, nature of disease, how to prevent and control them especially the small-scale poultry producers. This is likely to improve overall good practices of handling poultry and reduce the risk of disease spread of a variety of poultry diseases as well as the health consequences it poses to both animals and humans.
\end{abstract}

Keywords: Bird flu, Risk, Socioeconomic, Biosecurity, Poultry, Nigeria

\section{Background}

Nigeria was the first country in Africa to be affected by the H5N1 virus (bird flu) outbreaks in 2008. During 2008, the disease rapidly spread to 97 local government areas in Nigeria, and recently, in 2014 the disease resurfaced in Lagos and Rivers State of Nigeria (Obi et al. 2009; Okpukpara, 2015). The spread is exacerbated in Nigeria because of long porous borders and informal livestock movement across it, especially at border markets, resulting in illegal movement of poultry and poultry products into Nigeria. The bird flu outbreak caused a loss of approximately 890000 birds through

(c) The Author(s). 2016 Open Access This article is distributed under the terms of the Creative Commons Attribution 4.0 International License (http://creativecommons.org/licenses/by/4.0/), which permits unrestricted use, distribution, and reproduction in any medium provided you give appropriate credit to the original author(s) and the source, provide a link to the Creative Commons license, and indicate if changes were made. 
deaths and stamping out as in mid-June 2006 (the cost for the recent outbreak in 2014 is yet to be estimated). At an average farm gate price of about N700 per bird, the farm gate value of the birds lost was about N 617 million (or US\$ 4.8 million). These figures are based on official estimates, and are believed to be under estimated because the actual poultry population wiped out in rural areas remains unknown (Avian Influenza Controlled Project (AICP) (2014)).

Since its emergence, bird flu H5N1 strain has attracted considerable public and media attention because the virus has shown to be capable of causing fatal disease in humans, through mutation of the virus into a strain capable of sustained human-tohuman transmission. However, the greatest impact to date has been on the highly diverse poultry industries in affected areas in Nigeria. In response to this, policies against bird flu have so far focused on implementing prevention, control, and eradication measures in poultry industry. Until recently, significantly less emphasis has been placed on understanding producers' behavioral factors that may alter their knowledge, attitudes, and practices of disease prevention and control measures. Understanding the factors affecting behavior is important because in disease control setting conditions required to achieve the efficient outcome are often absent due to information problems resulting in market failures and/or coordination failures (Narrod et al. 2010, Jeong et al. 2014).

Due to stochastic forces and often complex interactions among players in the poultry value chains, it is not always clear to regulatory decision makers how to intervene optimally, particularly to ensure that poor producers participate in efforts to reduce the risk of a disease.

There have been numerous attempts to investigate KAP levels for bird flu on the general population (Fielding et al. 2005; Olsen et al. 2005; UNICEF-Georgia, 2007; Suphunnakul and Maton 2009; Di Giuseppe et al. 2008; Leslie et al. 2008) and on target groups (UNICEF-Myanmar, 2006; Leggat et al. 2007; Ameji, et al. 2012). An examination of the methodologies adopted by these studies is helpful in evaluating the strengths and weaknesses of various statistical tools that accommodate different types of research questions. Most of the studies described above differed in terms of the statistical methods used in their analyses. Some studies only utilized $t$ tests to identify significant differences in KAP scores between interest groups (Mahmoodabad et al. 2008; Ly et al. 2007; Xiang et al. 2010; Liebenehem et al. 2009; Negro-Calduch, et al. 2013). Some studies created binary KAP variables by categorizing KAP levels into groups (often negative and positive groups) (Kumar and Popat 2010; Leggat et al. 2007; Lau et al. 2007; Fielding et al. 2005); these studies restricted the scope of their analyses because regression coefficients could not capture the full variation in KAP levels or in factors that influence those scores. Some other authors limited the KAP indices to two or three points and hence did not capture as much variation in dependent variables and may not have fully measured the respondents' KAP (Imai et al. 2005; Mahmoodabad et al. 2008; Fielding et al. 2005; Tiongco et al. 2012). Leslie et al. (2008) improved the precision of their indices by weighting the responses to questions used in each index based on each question's importance in determining superior knowledge, attitudes, and practices on bird flu.

An examination of past KAP studies shows that the most effective methodologies used categorical KAP indices, conduct multivariate regressions to identify, and control 
for multiple influencing factors. Additionally, the results of previous KAP studies on animal diseases suggest that it is important to control for socioeconomic classes, regional factors, rural and urban settings as well as previous experience with animal diseases. This study considered these variables, in addition to information about beliefs and practices surrounding the management of sick or dead birds. This study is based on primary data collected through a household survey in 2010 and 2014 described in the Methods section. The findings of this study will help policymakers to formulate effective strategies to prevent and control disease outbreaks through identifying the factors responsible for knowledge, attitude, and practice of disease control.

The approach taken in this study is adapted from the theoretical frameworks developed by Huang (1993) and Jolly et al. (2009). Their models for economic analysis and decision making take into consideration the psychological, social, and other noneconomic factors that guide decision-makers' behavior. Huang's (1993) approach assumed that individual's perceptions were formulated from available information, knowledge, experiences as well as personal, social and cultural backgrounds. Jolly et al. (2009) extends Huang's approach and assumes that individual's perception about the problem affects knowledge and awareness, and in turn develops an attitude that will promote action to minimize risks. In this study, we assume that individual's perception about disease spread in the village is influenced by socioeconomic, regional and demographic factors as well as his knowledge and beliefs about highly pathogenic avian influenza (HPAI), before any action is taken to minimize risks.

\section{Methods}

This study was conducted in Nigeria using survey design. The survey was conducted in three states. Kano State, Anambra State, and Lagos State, which were considered high and medium risk areas for bird flu introduction and transmission based on the risk maps developed in the project. There are seven states classified as high and medium bird flu disease risk in terms of transmission and introduction. The high risk areas are Kano State, Borono State, Sokoto State, Lagos State, while medium risk areas are Anambra, Rivers, and Kastina. All other states in Nigeria are classified as low risk areas in bird flu introduction and transmission (National Bureau of Statistics (NBS) 2014, AICP (2014)). The choice of these three states were informed based on the fact that population of poultry producers in these states accounted for $67.5 \%$ of poultry producers in Nigeria (2013). In addition, the incidence of bird flu accounted for $80 \%$ of the entire disease incidence in Nigeria (NBS, 2014). Following the UNDP (2007) definitions of poultry production system, Nigeria poultry industry is classified into four production systems (backyard/free-range (BY), and small-scale (SS), and medium-scale (MS), and large-scale (LS). The sampling frame constitutes the entire household in the selected states. In fact, 97 and $75 \%$ of household in rural and urban Nigeria rear/own poultry, respectively (Obi et al. 2009). A complete listing of housing units and households in each selected enumeration area provided the frames of households (HHs) for the second stage selection in selected EAs. The total of 30 enumeration areas were sampled in each state based on poultry population, which was provided by poultry association of Nigeria (PAN) and Avian Influenza Control Project Office (AICP) in each of the selected states. Given the focus of the project was on the poor, the distribution of 
enumeration areas was skewed to rural areas. Therefore, 23 enumeration areas were selected in rural areas or peri-urban areas and 7 enumeration areas were selected in urban areas. From each of the enumeration areas 8 housing units were selected from each state creating a sample of 240 housing unit. In each of the 240 housing unit, three households were selected. This gives a total of 720 households.

A random selection of producers within each production system was also made. Ideally, this was done by selecting randomly from a list of poultry producers in each category. The final sample size was (after non-response and other data quality issues) 611 households out of which $73 \%$ (or 445) were located in rural or peri-urban areas. Table 1 below provides a distribution of households sampled across the states. However, Anambra State had limited number of medium and large-scale poultry farmers. Hence, this translates to very low sample size for those scales of production in the state.

\section{Estimation procedures}

In the household survey a total of 40 questions on knowledge, attitudes, perception, and practices (KAP) were asked. These questions were grouped into 5 categories: knowledge, beliefs, actions, reporting, and perception. These questions were framed as dichotomous questions (yes/no) or multiple choice questions that allowed multiple answers. For example, questions on practices or actions taken in preventing or controlling disease outbreaks were structured as dichotomous choice so as to capture differences or common practices of households within the study area. A Likert-type scale was used to elicit risk perceptions. For each category of KAP questions, responses were scored by awarding 1 point for each acceptable or correct answer and 0 for each wrong answer, and then scores were summed by category and by household to come up with an index.

The study estimated the three KAP regression models using ordinal logistic regression analysis to determine the likelihood of greater knowledge, beliefs, and perception. The three dependent variables were on a scale of between 0 and 5 where 0 is for unaware while 5 is fully aware. In other words, our dependent variables are the KAP indices where the scores are ordered taking on the values $\{0 ; 1 ; 2 ; \ldots$.$\} for some known$ integer $j$, where larger values are assumed to correspond to higher knowledge KAP, correct beliefs KAP, and higher concerns about transmission of disease or perception KAP (for construction of these indices and meaning see Appendix 1).

Following Green (2003), the starting point of our model is built around a latent regression in the same manner as the binomial probit model:

$$
y *=x^{\prime} \beta+\varepsilon
$$

where $y^{*}$ is unobserved. What the study observe is

Table 1 Sample size in different categories of poultry production system

\begin{tabular}{llllll}
\hline & $\begin{array}{l}\text { Free-range } \\
(<=50 \text { birds })\end{array}$ & $\begin{array}{l}\text { Small-scale } \\
(51-999 \text { birds })\end{array}$ & $\begin{array}{l}\text { Medium-scale } \\
(1000-5000 \text { birds })\end{array}$ & $\begin{array}{l}\text { Large-scale } \\
(>5000 \text { birds })\end{array}$ & All households \\
\hline Anambra & 163 & 34 & 5 & 1 & 203 \\
Lagos & 121 & 49 & 23 & 15 & 208 \\
Kano & 95 & 66 & 22 & 17 & 200 \\
\hline
\end{tabular}

Source: Field Survey, 2010 and 2014 


$$
\begin{aligned}
& y=0 \text { if } y * \leq 0 \\
& y=1 \text { if } 0 \leq y * \leq \mu_{1}, \\
& y=2 \text { if } 0 \leq y * \leq \mu_{2} \\
& y=j \text { if } \mu_{j-1}, \leq y *
\end{aligned}
$$

where the $\mu_{s}$ are unknown parameters to be estimated with $\beta$ and a set of cutpoints $\left(k_{i}\right)$ by maximizing the log-likelihood function:

$$
\ln L=\sum_{j=1}^{N} w_{j} \sum_{i=1}^{k} I_{i}\left(y_{j}\right) \ln p_{i j}
$$

where $w_{\mathrm{j}}$ is an optional weight and

$$
I_{i}\left(y_{j}\right)= \begin{cases}1, & \text { if } y_{i j}=i \\ 0, & \text { otherwise }\end{cases}
$$

The probability of observing outcome $y_{j}$ for ordered logit corresponds to the probability that the estimated linear function, plus random error, is within the range of the cutpoints estimated for the outcome:

$$
\begin{aligned}
& \operatorname{Pr}\left(y_{j}=1\right)=\operatorname{Pr}\left(\kappa_{i-1}<x_{j} \beta+u \leq \kappa_{i}\right) \\
& =\frac{1}{1+\exp \left(-\kappa_{i}+x_{j} \beta\right)}-\frac{1}{1+\exp \left(-\kappa_{i-1}+x_{j} \beta\right)}
\end{aligned}
$$

where $u$ is assumed to be logistically distributed, $\kappa_{0}$ is defined as $-\infty . \kappa_{k}$ is defined as $+\infty$ The probability of observing outcome $y_{j}$ for ordered probit is given by

$$
\begin{aligned}
& \operatorname{Pr}\left(y_{j}=1\right)=\operatorname{Pr}\left(\kappa_{i-1}<x_{j} \beta+u \leq \kappa_{i}\right) \\
& =\Phi\left(\kappa_{i}-x_{j} \beta\right)-\Phi\left(\kappa_{i}-x_{j} \beta\right)
\end{aligned}
$$

where $\Phi($.$) is the standard normal cumulative distribution function.$

The odds ratio is assumed constant or the same for all categories and is independent of each category, so if the study considered the odds $(k)=P(Y \leq k) / P(Y>k)$, then odds $(k 1)$ and $(k 2)$ have the same ratio for all independent variable combinations (StataCorp, 2009). The proportional odds ordered logit model is based on the principle that the only effect of combining adjoining categories in ordered categorical regression problems should be a loss of efficiency in estimating the regression parameters (McCullagh 1977). This model was also described by McKelvey and Zavoina (1975) and, previously by Aitchison and Silvey (1957) in a different algebraic form. Brant (1990) offers a set of diagnostics for the model.

One of the questions the study asked in the series of KAP analysis is whether and how the past experience with poultry disease affects the KAP index levels. However, there is a possibility that the disease experience and KAP levels are endogenously determined. In other words, past disease experience may affect KAP levels of a producer, but KAP levels may also have affected whether the producer's poultry had disease in the past or not. Because the presence of endogeneity can affect the statistical nature of the results, for each of the three regression models, the study tested for the endogeneity between disease experience and KAP index levels. The study applied an endogenous switching model described in Miranda and Rabe-Hesketh (2006), where the study hypothesized that those producers with past disease experience may have different 
response regarding knowledge or beliefs, or perception of the disease. To illustrate, knowledge KAP is assumed to depend on the endogenous dummy disease outbreak in the village or not (defined as ifdisease in Table 5) and a $K \times 1$ vector of explanatory variables (including the constant term), $\boldsymbol{x}_{i}$. Similarly, the endogenous dummy ifdisease $e_{i}$ depends on an $L \times 1$ vector of explanatory variables (including the constant term), $z_{i}$. Vectors $\boldsymbol{x}_{\boldsymbol{i}}$ and $z_{\boldsymbol{i}}$ may contain identical elements considering that there is no exclusion restrictions needed to identify the model (Wilde 2000).

\section{Estimation of knowledge KAP}

The study began our empirical analysis with the estimation of the determinants of knowledge KAP index. While the theoretical value of this index is between 0 and 5 in the model, the actual levels of the index for Nigeria producers in the sample range between 0 and 4 . Using the knowledge KAP index as the dependent variable, the study considered the dependent variable level as an outcome of three related but separate forces: (1) access to information, (2) ability to obtain information, and (3) eagerness to obtain information.

\section{Estimation of beliefs KAP}

The study, estimated the determinants of beliefs KAP index, which characterize the number of good practices and safe handling of poultry and poultry products that the producers believe in. In view of the fact that many of the items in the list of practices pertain to those as consumer of poultry products, the study also included relevant household characteristics in the regression as explanatory variables.

\section{Estimation of perception KAP}

The study estimated the determinants of perception KAP index, which is a categorical variable that takes the value of 1 when the producer is least concerned about disease spread within a village when there is a disease case in the village and the value of 4 when the producer is most concerned. The study considered that the level of concern about disease spread within a village as an outcome of how correctly and rationally the producers can assess the risk of disease spread as well as the circumstances in which the producers operate. The study used an ordered logit model to capture this scenario.

\section{Results and discussion}

\section{Production practices and poultry keeping behavior}

Table 2 summarizes the poultry keeping practices of the household's survey. Nearly half of all free-range and small producers reported keeping the birds in wooden cages. The second most common practice was open floors in the cages. The medium and larger farms predominately had separate poultry farms.

\section{Information about bird flu}

First, the small-scale producers and free rangers indicated higher scores compared to larger scale producers in terms of knowledge about bird flu symptoms. This is probably due to the fact that bird flu symptoms are similar to clinical signs of other common poultry diseases such as new castle disease. Medium and large-scale producers on the 
Table 2 Practices associated with poultry keeping in Nigeria

\begin{tabular}{lllll}
\hline & $\begin{array}{l}\text { Free-range } \\
(N=379)\end{array}$ & $\begin{array}{l}\text { Small-scale } \\
(N=149)\end{array}$ & $\begin{array}{l}\text { Medium-scale } \\
(N=50)\end{array}$ & Large-scale \\
& Percent & Percent & Percent & Percent \\
\hline Wooden cage & 56.75 & 49.3 & 0 & 0 \\
Basket & 5.01 & 6.24 & 0 & 0 \\
Mud/thatch house & 7.91 & 11.12 & 0 & 0 \\
Fenced backyard & 10.02 & 17.14 & 12.64 & 8.88 \\
Open floor in house & 16.62 & 11.79 & 9.19 & 0 \\
Tree/bush on land & 3.69 & 4.41 & 0 & 0 \\
Poultry farm & 0 & 0 & 78.17 & 91.12 \\
\hline
\end{tabular}

Source: Field Survey, 2014

other hand had higher KAP index scores on beliefs on safe practices, past actions of disposing of dead birds, and past actions of risk mitigation practices and reporting sick birds compared to smaller-sized producers. Scores on perception of disease transmission are almost the same across different size producers though small, indicating equal perception of bird flu transmission among poultry producers in Nigeria.

Secondly, information about bird flu was largely gathered through media outlets such as television (44\%) and radio (34\%) (see Table 3). Animal health officers and extension services also play an important role in the dissemination of information, accounting for 5 and 7\% of respondents, respectively. Others sources of information on bird flu, including flyers (3\%), input suppliers (1\%), and village heads (2\%) play minor roles in the dissemination of information to the households..

\section{Actual biosecurity practices}

Biosecurity-related activities commonly carried out by the households surveyed included checking poultry house daily for dead or sick birds (87\%), placing in quarantine newly purchased poultry (50\%), checking the symptoms of diseases before purchasing new poultry (63\%), and frequently cleaning floors and cages of feces (75\%). These practices, though not necessarily specific to bird flu, vary considerably across different size producers, with higher percentage practiced by medium and large producers.

Table 3 Sources of information about bird flu after 2006 in Nigeria

\begin{tabular}{lll}
\hline Source of information & Number of households & Percent \\
\hline Television & 270 & 44 \\
Flyer & 18 & 3 \\
Animal health officer & 33 & 5 \\
Extension Service & 42 & 7 \\
Supplier & 5 & 1 \\
Village head & 12 & 2 \\
Radio & 205 & 34 \\
Poultry association & 5 & 1 \\
Other & 21 & 3 \\
\hline
\end{tabular}

Source: Field Survey, 2014 
Table 4 shows the type of biosecurity measures reportedly being used by different flock sizes. Nearly all of the medium-scale producers reported keeping the doors closed at all times (99\%), while less of the free-range and small-scale producers practiced this measure (29\% for free-range and 65\% small-scale). For every biosecurity measure except frequently cleaning feces from the floor and cages, the proportion of households that practiced certain measures is positively associated with the scale of operation. Although $50 \%$ of all size producers reported quarantining new birds prior to having them

Table 4 Biosecurity preventive measures undertaken by poultry producers in Nigeria

\begin{tabular}{|c|c|c|c|c|c|}
\hline Biosecurity measure & Free-range & Small-scale & Medium-scale & Large-scale & All households \\
\hline $\begin{array}{l}\text { Closed doors in poultry house all } \\
\text { the time }\end{array}$ & $55.4 \%$ & $75.0 \%$ & $80.4 \%$ & $76.7 \%$ & $63.5 \%$ \\
\hline $\begin{array}{l}\text { Check poultry house daily for dead } \\
\text { or sick birds }\end{array}$ & $83.4 \%$ & $92.0 \%$ & $93.5 \%$ & $92.9 \%$ & $86.9 \%$ \\
\hline $\begin{array}{l}\text { Kept same poultry cage during the } \\
\text { outbreak in village }\end{array}$ & $71.0 \%$ & $82.9 \%$ & $82.2 \%$ & $82.1 \%$ & $75.5 \%$ \\
\hline Quarantined newly purchased poultry & $56.4 \%$ & $68.3 \%$ & $72.3 \%$ & $78.5 \%$ & $62.0 \%$ \\
\hline $\begin{array}{l}\text { Check the symptoms of diseases } \\
\text { before purchase }\end{array}$ & $78.4 \%$ & $84.1 \%$ & $87.0 \%$ & $86.2 \%$ & $80.9 \%$ \\
\hline $\begin{array}{l}\text { Used all-in and all-out method for } \\
\text { each type of poultry }\end{array}$ & $57.3 \%$ & $72.7 \%$ & $80.6 \%$ & $73.7 \%$ & $64.8 \%$ \\
\hline $\begin{array}{l}\text { Monitored contact between your's } \\
\text { and neighbors' poultry }\end{array}$ & $50 \%$ & $67.6 \%$ & $79.5 \%$ & $73.1 \%$ & $58.3 \%$ \\
\hline $\begin{array}{l}\text { Monitored contact between your's } \\
\text { and wild poultry }\end{array}$ & $47.8 \%$ & $70.9 \%$ & $81.6 \%$ & $64.3 \%$ & $57.8 \%$ \\
\hline All visitors cleaned with disinfectant & $29.3 \%$ & $42.2 \%$ & $65.8 \%$ & $56.7 \%$ & $38.4 \%$ \\
\hline All visitors changed clothes & $26.0 \%$ & $31.7 \%$ & $42.1 \%$ & $33.3 \%$ & $29.6 \%$ \\
\hline $\begin{array}{l}\text { Frequently cleaned floors and cages } \\
\text { from feces }\end{array}$ & $77.6 \%$ & $84.6 \%$ & $86.0 \%$ & $85.2 \%$ & $80.5 \%$ \\
\hline $\begin{array}{l}\text { Total number of biosecurity } \\
\text { measures implemented }\end{array}$ & 4.92 & 6.23 & 7.20 & 8.89 & 5.52 \\
\hline $\begin{array}{l}\text { Closed doors in poultry house } \\
\text { all the time }\end{array}$ & $55.4 \%$ & $75.0 \%$ & $80.4 \%$ & $76.7 \%$ & $63.5 \%$ \\
\hline $\begin{array}{l}\text { Check poultry house daily for dead } \\
\text { or sick birds }\end{array}$ & $83.4 \%$ & $92.0 \%$ & $93.5 \%$ & $92.9 \%$ & $86.9 \%$ \\
\hline $\begin{array}{l}\text { Kept same poultry cage during the } \\
\text { outbreak in village }\end{array}$ & $71.0 \%$ & $82.9 \%$ & $82.2 \%$ & $82.1 \%$ & $75.5 \%$ \\
\hline Quarantined newly purchased poultry & $56.4 \%$ & $68.3 \%$ & $72.3 \%$ & $78.5 \%$ & $62.0 \%$ \\
\hline $\begin{array}{l}\text { Check the symptoms of diseases } \\
\text { before purchase }\end{array}$ & $78.4 \%$ & $84.1 \%$ & $87.0 \%$ & $86.2 \%$ & $80.9 \%$ \\
\hline $\begin{array}{l}\text { Used all-in and all-out method for } \\
\text { each type of poultry }\end{array}$ & $57.3 \%$ & $72.7 \%$ & $80.6 \%$ & $73.7 \%$ & $64.8 \%$ \\
\hline $\begin{array}{l}\text { Monitored contact en between your's } \\
\text { and neighbors' poultry }\end{array}$ & $50 \%$ & $67.6 \%$ & $79.5 \%$ & $73.1 \%$ & $58.3 \%$ \\
\hline $\begin{array}{l}\text { Monitored contact between your's } \\
\text { and wild poultry }\end{array}$ & $47.8 \%$ & $70.9 \%$ & $81.6 \%$ & $64.3 \%$ & $57.8 \%$ \\
\hline All visitors cleaned with disinfectant & $29.3 \%$ & $42.2 \%$ & $65.8 \%$ & $56.7 \%$ & $38.4 \%$ \\
\hline All visitors changed clothes & $26.0 \%$ & $31.7 \%$ & $42.1 \%$ & $33.3 \%$ & $29.6 \%$ \\
\hline $\begin{array}{l}\text { Frequently cleaned floors and cages } \\
\text { from feces }\end{array}$ & $77.6 \%$ & $84.6 \%$ & $86.0 \%$ & $85.2 \%$ & $80.5 \%$ \\
\hline $\begin{array}{l}\text { Total number of biosecurity measures } \\
\text { implemented }\end{array}$ & 4.92 & 6.23 & 7.20 & 8.89 & 5.52 \\
\hline
\end{tabular}

Source: Field Survey, 2010 and 2014 
join the flock, the medium and small-scale producers tended to follow an all-in and allout method for each type of poultry, whereas free-range producers rarely (18\%) used this method. On average, few producers reported requiring visitors to change clothes (5\%), although medium-scale producers tend to use this method more frequently (30\%).

\section{Econometric estimation of KAP}

The study tried count model estimation (negative binomial and Poisson regressions). The Poisson model was found to fit well with the data, which is count data. The use of Poisson regression over the negative binomial regression was based on the fact that the data is count variable and the majority of the poultry farmers in the data answered positively, but a few poultry farmers had zero response. In addition, the statistical test rejected the null hypothesis of over dispersion in negative binomial model. Subsequently, a test for the endogeneity of the past poultry disease experience and knowledge KAP was carried out by applying an endogenous switching model described in Miranda and Rabe-Hesketh (2006), where the study hypothesized that those producers with previous disease experience may have different response regarding knowledge KAP, dummy of past disease experience in the village was used as the switching variable. The column (2) of Table 5 lists the results of Poisson regression for knowledge KAP.

While the overall predictive power of the estimation is relatively low $(R 2=0.0674)$, there are some important findings from the estimate. The relatively low predictive power implied that some variables, which may significantly affect the dependent variable (KAP), were outside the scope of this study, hence were excluded from the model. First, the study found that knowledge about bird flu symptoms is higher for households with higher income indicating that these farmers have more resources to obtain knowledge. This finding is in consonant with a survey of knowledge, attitudes, and practices towards avian influenza in an adult population of Italy, which had low predictive power as well as the positive correlation between the household income and knowledge about the flu symptoms (Di Giuseppe et al. 2008). Second, knowledge about bird flu symptoms is higher among farmers raising layers, likely reflecting that owners of layers are more motivated to acquire information about poultry diseases since more is at stake for these producers in poultry health management. Third, the regression results indicate that knowledge KAP is higher for those producers that had poultry disease in their flocks in the past, which is as expected as past experience contributes to their knowledge. Similar findings have been reported elsewhere in Egypt, which identified that biosecurity measures are rarely implemented in small-scale commercial poultry production units as well as those with past disease experience had higher KAP in that region (Negro-Calduch et al. 2013)

Fourth, the study found that knowledge KAP is lower in Kano relative to Anambra and Lagos. This is expected because the poultry farmers in Kano State are less educated than those in Anambra and Lagos. Fifth, larger household did not capture larger exposure of knowledge about Bird Flu because there is a common source of information for larger and smaller households.

In terms of beliefs KAP, the study applied count model estimation (negative binomial and Poisson regressions) and ordered probit regression. Ordered probit regression was chosen because the nature of the data generated as well as the fact that count model 
Table 5 Determinants of knowledge about bird flu symptoms, beliefs in good practices, and safe handling of poultry and poultry products, and perceptions of bird flu transmission

\begin{tabular}{|c|c|c|c|}
\hline & $\begin{array}{l}\text { (1) Poisson } \\
\text { regression }\end{array}$ & $\begin{array}{l}\text { (2) Ordered } \\
\text { probit }\end{array}$ & $\begin{array}{l}\text { (3) Ordered } \\
\text { logit }\end{array}$ \\
\hline & Knowledge KAP & Beliefs KAP & $\begin{array}{l}\text { Perception } \\
\text { KAP }\end{array}$ \\
\hline \multirow[t]{2}{*}{ Index on knowledge on Al symptoms (number) } & & $0.1288^{* * *}$ & 0.1677 \\
\hline & & $(0.0499)$ & $(0.1031)$ \\
\hline \multirow[t]{2}{*}{ Index on beliefs about good practices (number) } & & & $0.6533^{* * *}$ \\
\hline & & & $(0.1220)$ \\
\hline \multirow[t]{2}{*}{ Head's years of poultry raising experience (years) } & 0.0062 & -0.0097 & -0.0161 \\
\hline & $(0.0094)$ & $(0.0078)$ & $(0.0153)$ \\
\hline \multirow[t]{2}{*}{ Number of people in $\mathrm{HH}$ (number) } & $-0.0591^{* *}$ & & 0.0010 \\
\hline & $(0.0293)$ & & $(0.0513)$ \\
\hline \multirow{2}{*}{$\begin{array}{l}\mathrm{HH} \text { has child }<12 \text { years old (dummy }=1 \text { if the household } \\
\text { had children less than } 12 \text { years, } 0 \text { otherwise) }\end{array}$} & & $-0.3624^{* * *}$ & -0.2443 \\
\hline & & $(0.1150)$ & $(0.2225)$ \\
\hline \multirow[t]{2}{*}{ Head is female (dummy I if head is female; 0 otherwise) } & 0.1655 & 0.1886 & 0.1568 \\
\hline & $(0.1587)$ & $(0.1620)$ & $(0.2954)$ \\
\hline \multirow[t]{2}{*}{ Head's years of education (number) } & 0.0186 & 0.0245 & 0.0031 \\
\hline & $(0.0316)$ & $(0.0291)$ & $(0.0549)$ \\
\hline \multirow[t]{2}{*}{ Head's years of education, squared (number) } & -0.0007 & -0.0009 & 0.0006 \\
\hline & $(0.0016)$ & $(0.0015)$ & $(0.0028)$ \\
\hline \multirow[t]{2}{*}{ Ln_totinc: log of total HH income (number) } & $0.0350^{*}$ & 0.0137 & -0.0085 \\
\hline & $(0.0189)$ & $(0.0109)$ & $(0.0264)$ \\
\hline \multirow[t]{2}{*}{ Log of layer flock size (number) } & $0.0242^{* *}$ & -0.0061 & 0.0088 \\
\hline & $(0.0104)$ & $(0.0095)$ & $(0.0184)$ \\
\hline \multirow[t]{2}{*}{ Log of total poultry flock size (number) } & & -0.0058 & -0.0225 \\
\hline & & $(0.0116)$ & $(0.0213)$ \\
\hline \multirow[t]{2}{*}{ Distance to nearest poultry farm $(\mathrm{km})$} & -0.0005 & & 0.0005 \\
\hline & $(0.0022)$ & & $(0.0028)$ \\
\hline \multirow[t]{2}{*}{ Distance to animal health shop (km) } & -0.0037 & & \\
\hline & $(0.0053)$ & & \\
\hline \multirow{2}{*}{$\begin{array}{l}\text { Outbreak of disease in village (dummy }=1 \text { if there ever } \\
\text { been an Al outbreak in the village) }\end{array}$} & $0.3457^{* * *}$ & $0.3651^{* * *}$ & $0.4228^{* *}$ \\
\hline & $(0.1195)$ & $(0.1100)$ & $(0.2055)$ \\
\hline \multirow[t]{2}{*}{ Kano (dummy = 1 if $\mathrm{HH}$ is from Kano; 0 otherwise) } & $-1.1122^{* * *}$ & -0.0192 & -0.2548 \\
\hline & $(0.2522)$ & $(0.1370)$ & $(0.2749)$ \\
\hline \multirow{2}{*}{$\begin{array}{l}\text { Anambra (dummy }=1 \text { if } \mathrm{HH} \text { is from Anambra } 0 \\
\text { otherwise) }\end{array}$} & -0.3017 & 0.0681 & $-0.8581^{* * *}$ \\
\hline & $(0.2412)$ & (0.1388) & $(0.2850)$ \\
\hline \multirow[t]{2}{*}{ Constant } & 0.1287 & & \\
\hline & $(0.3176)$ & & \\
\hline \multirow[t]{2}{*}{ Cut1 } & & -0.0861 & $1.8273^{*}$ \\
\hline & & $(0.2168)$ & $(0.9337)$ \\
\hline \multirow[t]{2}{*}{ Cut2 } & & $0.5676^{* * *}$ & $4.3409^{* * *}$ \\
\hline & & $(0.2178)$ & $(0.9583)$ \\
\hline \multirow[t]{2}{*}{ Cut3 } & & & $5.8744^{* * *}$ \\
\hline & & & (0.9776) \\
\hline Observations & 345 & 504 & 382 \\
\hline
\end{tabular}


Table 5 Determinants of knowledge about bird flu symptoms, beliefs in good practices, and safe handling of poultry and poultry products, and perceptions of bird flu transmission (Continued)

\begin{tabular}{llll}
\hline Log-likelihood & -424.665 & -518.0708 & -454.1188 \\
chi2 & 61.39 & 39.3051 & 71.0058 \\
$p$ value & 0.000 & 0.0001 & 0.0000 \\
Pseudo R2 & 0.0674 & 0.0365 & 0.0725 \\
\hline
\end{tabular}

Standard errors in parentheses

${ }^{*} p<0.10,{ }^{* *} p<0.05,{ }^{* * *} p<0.01$

Source: Field Survey, 2014

were found to be statistically insignificant. The result of standard ordered probit regression showed different degrees of influence on belief. The coefficients on the explanatory variables are interpreted as the contributions of the variables to the probability of falling into correct beliefs about good practices. A positive coefficient implies a larger probability that a subject with a larger value of the independent variable will be observed in a higher bin or category. A negative coefficient implies that a subject with a larger value of the independent variable is likely to be observed in a lower bin or category. The "cuts" in the table are interpreted as the cutoff points between the bins: cut 1 is a cut-off point between beliefs $\mathrm{KAP}=0$ and beliefs $\mathrm{KAP}=1$, and cut 2 between beliefs $\mathrm{KAP}=1$ and beliefs $\mathrm{KAP}=2$. For example, the probability that beliefs KAP falls in 0 is denoted as $\operatorname{Pr}($ beliefs $\mathrm{KAP}=0)=\operatorname{Pr}(\mathrm{Xb}+\mathrm{u}<$ cut 1$)$, where $\mathrm{Xb}$ represents the linear regression model and $u$ is the error term.

The column (2) of Table 5 lists the results of ordered probit regression for beliefs KAP. Again the predictive power of the estimation is low $(R 2=0.0365)$, but the model is statistically significant. There are important findings from this result. First, knowledge KAP index significantly influenced the beliefs KAP index as expected. This implies that producers who are knowledgeable about Bird Flu symptoms are likely to believe in good practices and safe handling of poultry products in order to reduce the risk of Bird Flu. Second, past experience with poultry disease in the household's own flock positively influenced beliefs KAP, reflecting the hypothesis that these producers tend to have higher incentives to be aware of good practices and to form correct beliefs. This finding is supported by (Ameji et al., 2012). Third, the dummy variable of whether the household has a child is negatively associated with beliefs KAP, suggesting that child presence reduces the chances of the household's beliefs about good practices and safe handling of sick and dead poultry.

In terms of perception, the study considered that the level of concern about disease spread within a village is an outcome of how correctly and rationally the producers can assess the risk of disease spread as well as the circumstances in which the producers operate. The column (3) of Table 5 lists the results of ordered logit regression for perception KAP. Three important observations emerge from the regression results. First, beliefs KAP index is significantly and positively associated with perception KAP. This means that those producers who believe in good practices and safe handling of sick or dead poultry have higher concerns about disease spread risks. Second, producers with experience with poultry diseases are more concerned with disease spread within a village. Third, the concerns for disease spread are lower among producers located in Anambra where free-range and small-scale producers dominate. This suggests that smaller producers are riskier in terms of disease transmission considering that their concern about disease spread is lower compared to large and medium-scale producers. 


\section{Determinants of actual biosecurity actions}

To conclude the KAP analysis, the study estimated the determinants of actual biosecurity practices currently adopted by the producers. Using the responses to the questions regarding the eleven biosecurity measures discussed in the descriptive statistics (see Appendix 2), the study implemented two regressions. First, the study constructed a count variable that represents the total number of biosecurity actions among the 11 that the producers currently implement. Thus, this used count variable as the dependent variable. Second, by stacking the binary responses (yes or no) to all of the 11 biosecurity actions, the study implemented panel data probit (random effects probit) to estimate what influences the probability that the producers adopt the 11 biosecurity practices. In this regression, each producer has eleven observations.

Both sets of models include the same set of explanatory variables. First, all three KAP indices are included in the estimation model to analyze how knowledge, beliefs, and perception about disease and disease risks influence actual biosecurity decisions. For the random effects probit estimation, the study also included dummy variables representing each of the biosecurity actions. The endogeneity of actual biosecurity and the past poultry disease experience (ifdisease) was tested and rejected.

The regression results are presented in Table 6. The results are almost similar for Poisson regression and the random-effects probit regression. One important finding from these regressions is that KAP indices are found unimportant in explaining the actual biosecurity decisions of the Nigerian producers. This implies that there is some disconnect between the formation of knowledge, beliefs in good practices, and perception about disease risks transmission and the biosecurity practices that the producers actually adopt. Understanding this disconnect seems most imperative in designing public policies intended to encourage small poultry producers to adopt biosecurity measures in Nigeria. Further, the study identified that the biosecurity adoption levels and probability are positively associated with education of the household head, which did not appear significant in the KAP indices regression results. This implies that household education and outreach program may be effective in influencing household biosecurity behavior. Finally, the study found that producers with past experience with poultry diseases and those farmers involved in layers production implemented more biosecurity actions or increase their subjective probability in adopting biosecurity actions. Regional dummies (Kano and Anambra) were not statistically significant, which implies that locations had no influence on biosecurity practices.

\section{Summary, implications, and policy conclusions}

Analyses of the three KAP indices on knowledge about bird flu symptoms (knowledge $\mathrm{KAP}$ ), beliefs about safe practices handling poultry and products (beliefs KAP), and perception on disease risk transmission (perception KAP) revealed important determinants in the decision-making process of poultry producers. In the case of knowledge KAP, important factors that contribute to higher level of knowledge about bird flu symptoms are higher education level of household head (particularly for those producers with more than 13 years of education),incidence of poultry disease in the past 5 years, and households from regions where outbreaks occurred. Moreover, those producers with higher knowledge about bird flu symptoms are more likely to believe in good practices about handling poultry and poultry products and are found to have higher concerns about disease spread risks. It is possible 
Table 6 Estimation results of actual biosecurity actions amongst poultry producers in Nigeria

\begin{tabular}{|c|c|c|}
\hline & $\begin{array}{l}\text { Poisson } \\
\text { biosecurity }\end{array}$ & $\begin{array}{l}\text { Random effects } \\
\text { probit }\end{array}$ \\
\hline \multirow[t]{2}{*}{ Index on knowledge on Al symptoms } & 0.0176 & -0.0103 \\
\hline & $(0.0237)$ & $(0.0707)$ \\
\hline \multirow[t]{2}{*}{ Index on beliefs on good practices handling poultry products } & -0.0055 & 0.0730 \\
\hline & $(0.0307)$ & $(0.0895)$ \\
\hline \multirow[t]{2}{*}{ Perception of disease risk ( 1 is high risk; 4 is no risk) } & -0.0255 & 0.1367 \\
\hline & $(0.0285)$ & $(0.0873)$ \\
\hline \multirow[t]{2}{*}{ B1: Head's years of poultry raising experience } & -0.0027 & 0.0004 \\
\hline & $(0.0038)$ & $(0.0112)$ \\
\hline \multirow[t]{2}{*}{ Hhsize: number of people in $\mathrm{HH}$} & 0.0043 & -0.0061 \\
\hline & $(0.0123)$ & $(0.0362)$ \\
\hline \multirow[t]{2}{*}{ hhhgen: head is female } & 0.0895 & 0.0741 \\
\hline & $(0.0734)$ & $(0.2157)$ \\
\hline \multirow[t]{2}{*}{ Hhhedu: Head's yrs of education } & $0.0361^{* * *}$ & $0.0672^{*}$ \\
\hline & $(0.0137)$ & $(0.0398)$ \\
\hline \multirow[t]{2}{*}{ Hhhedu2: Head's yrs of education, squared } & $-0.0015^{* *}$ & -0.0024 \\
\hline & $(0.0007)$ & $(0.0021)$ \\
\hline \multirow[t]{2}{*}{ Child: dummy 1 if $\mathrm{HH}$ has child $<12$ years old } & 0.0854 & $0.3011^{*}$ \\
\hline & $(0.0536)$ & $(0.1619)$ \\
\hline \multirow[t]{2}{*}{ Ln of total HH income } & 0.0097 & 0.0121 \\
\hline & $(0.0076)$ & $(0.0207)$ \\
\hline \multirow[t]{2}{*}{ Ln_total_poultry: log of total poultry flock size } & -0.0000 & -0.0101 \\
\hline & $(0.0055)$ & $(0.0159)$ \\
\hline \multirow[t]{2}{*}{ Layer: log of layer flock size } & $0.0096^{* *}$ & $0.0346^{* *}$ \\
\hline & $(0.0046)$ & $(0.0141)$ \\
\hline \multirow[t]{2}{*}{ dis_farm: distance to nearest poultry farm } & 0.0005 & 0.0001 \\
\hline & $(0.0006)$ & $(0.0019)$ \\
\hline \multirow[t]{2}{*}{ dis_ahealth: distance to animal health shop } & -0.0001 & -0.0003 \\
\hline & $(0.0008)$ & $(0.0023)$ \\
\hline \multirow{2}{*}{$\begin{array}{l}\text { ifdisease: dummy }=1 \text { if there ever been an Al outbreak in } \\
\text { the village }\end{array}$} & 0.0791 & $0.3014^{*}$ \\
\hline & $(0.0522)$ & $(0.1557)$ \\
\hline \multirow[t]{2}{*}{ Kano: dummy $=1$ if $\mathrm{HH}$ is from Kano } & -0.0487 & -0.0501 \\
\hline & $(0.1107)$ & $(0.3183)$ \\
\hline \multirow[t]{2}{*}{ Anambra: dummy $=1$ if $\mathrm{HH}$ is from Anambra } & -0.0594 & 0.0914 \\
\hline & $(0.1107)$ & $(0.3190)$ \\
\hline \multirow[t]{2}{*}{ Constant } & $1.5915^{* * *}$ & \\
\hline & $(0.2447)$ & \\
\hline \multirow[t]{2}{*}{ Closed doors in poultry house all the time } & & $1.3223^{* * *}$ \\
\hline & & $(0.1539)$ \\
\hline \multirow[t]{2}{*}{ Checked poultry house daily for dead or sick birds } & & $2.6862^{* * *}$ \\
\hline & & $(0.1849)$ \\
\hline \multirow[t]{2}{*}{ Kept poultry in the cage during the outbreak in the village } & & $1.7969^{* * *}$ \\
\hline & & $(0.1609)$ \\
\hline Quarantined new purchased poultry & & $1.2388^{* * *}$ \\
\hline
\end{tabular}


Table 6 Estimation results of actual biosecurity actions amongst poultry producers in Nigeria (Continued)

\begin{tabular}{|c|c|c|}
\hline & & $(0.1551)$ \\
\hline \multirow[t]{2}{*}{ Checked the symptoms of diseases before purchase } & & $1.9897^{* * *}$ \\
\hline & & $(0.1617)$ \\
\hline \multirow[t]{2}{*}{ Monitor interaction/contact between yours and neighbors' poultry } & & $1.3345^{* * *}$ \\
\hline & & $(0.1600)$ \\
\hline \multirow[t]{2}{*}{ Monitored contact between your poultry and wild poultry } & & $1.3554^{* * *}$ \\
\hline & & $(0.1624)$ \\
\hline \multirow{2}{*}{$\begin{array}{l}\text { All visitors visiting the house or livestock farm are required to } \\
\text { clean with disinfectant (go through foot bath) }\end{array}$} & & $0.2923^{*}$ \\
\hline & & $(0.1640)$ \\
\hline \multirow[t]{2}{*}{ Frequently cleaned floors and cages from feces } & & $2.3099^{* * *}$ \\
\hline & & $(0.1702)$ \\
\hline \multirow[t]{2}{*}{ Operate an all-in-all-out policy for each batch/cycle } & & $1.2967^{* * *}$ \\
\hline & & $(0.1736)$ \\
\hline \multirow[t]{2}{*}{ Constant } & -1.1562 & $-2.0563^{* *}$ \\
\hline & $(1.0317)$ & $(0.8031)$ \\
\hline \multirow[t]{2}{*}{ Insig2u } & & 0.0502 \\
\hline & & $(0.1419)$ \\
\hline \multirow[t]{2}{*}{ Constant } & $-0.3014^{* * *}$ & \\
\hline & $(0.0750)$ & \\
\hline \multicolumn{3}{|l|}{ Load } \\
\hline \multirow[t]{2}{*}{ Constant } & $8.8356^{*}$ & \\
\hline & $(5.2360)$ & \\
\hline Observations & 611 & 2673 \\
\hline Log-likelihood & -979.0981 & -1247.9915 \\
\hline chi2 & 70.4866 & 387.0977 \\
\hline chi2_c & & 394.7225 \\
\hline$P$ & 0.0000 & 0.0000 \\
\hline \multirow[t]{2}{*}{ Sigma } & -0.3014 & 1.0254 \\
\hline & $(0.0750)$ & $(0.0727)$ \\
\hline \multirow[t]{2}{*}{ Rho } & 0.9362 & 0.5125 \\
\hline & $(2.3190)$ & $(0.0354)$ \\
\hline
\end{tabular}

*** $p<0.01, * * p<0.05, * p<0.1$

Standard errors in parentheses

Source: Field Survey, 2014

that poultry is important for these producers so they tend to have higher incentives to form correct beliefs and to be aware about good practices. Furthermore, those producers with higher knowledge or beliefs KAP score are able to make more informed and rational assessment of true disease spread risks.

The role of knowledge, beliefs, and perception about disease and disease risks in actual decisions regarding biosecurity practices by the producers showed that the KAP indices are not significantly associated with actual biosecurity decisions of poultry producers. This implies that there is some disconnect between the formation of knowledge, beliefs, and perception about disease and disease risks and the biosecurity practices the producers adopt. The study also found that the practices of biosecurity or the probability to practice 
were lower in villages that have had suspected or confirmed cases of bird flu. It is possible that producers lower their perceptions about the effectiveness of biosecurity measures when faced with actual bird flu outbreak in the village. It is important to understand this disconnect and demonstrate the effectiveness of biosecurity measures in order to encourage small poultry producers to adopt biosecurity measures in Nigeria. The study also found that adoption of biosecurity actions depends on flock size, specifically, smaller and poorer producers adopt fewer biosecurity actions, thus are considered to be riskier in terms of transmission risks.

Analyses of the three KAP indices on knowledge about bird flu symptoms (knowledge KAP), beliefs about safe practices handling poultry and products (beliefs KAP), and perception on disease risk transmission (perception KAP) revealed important determinants in the decision-making process of poultry producers. In the case of knowledge KAP, important factors that contribute to higher level of knowledge about bird flu symptoms are education level of household head, households headed by female, and households from regions where outbreaks occurred. Moreover, those producers with higher knowledge about bird flu symptoms are more likely to believe in good practices about handling poultry and poultry products and are found to have higher concerns about disease spread risks.

The role of knowledge, beliefs, and perception about disease and disease risks in actual decisions regarding biosecurity practices by the producers showed that smaller and poorer producers adopted fewer biosecurity actions, thus were considered to be riskier in terms of transmission risks. The biosecurity adoption levels and probability are positively associated with education, household income, and those farmers producing layers. Therefore, enhancing the operations of smaller producers for more effective commercialized operation will enhance their income and raise biosecurity adoption levels and reduce disease risk transmission (Table 7).

\section{Conclusions}

Analyses of the EBKAP indices on knowledge about HPAI symptoms revealed important determinants in the decision making process of poultry producers. In the case of knowledge KAP, important factors that contribute to higher level of knowledge about HPAI symptoms are higher education level of household head, incidence of poultry disease in the past 5 years as they learn through experience, and households from regions where outbreaks occurred. Moreover, those producers with higher knowledge about HPAI symptoms are more likely to believe in good practices about handling poultry and poultry products and are found to have higher concerns about disease spread risks. It is possible that poultry is important for these producers so they tend to have higher incentives to form correct beliefs and to be aware about good practices. Furthermore, those producers with higher knowledge or beliefs KAP score are able to make more informed and rational assessment of true disease spread risks.

The findings generated in this study are important for policy makers as they formulate effective strategies to prevent and control disease outbreaks. Education programs targeted at improving knowledge of HPAI symptoms will likely improve overall good practices of handling poultry and reduce the risk of disease spread of a variety of poultry diseases. Improving knowledge of both men and women about HPAI and its effect on human health is imperative to increasing adoption of actual biosecurity measures. The role of other socio-economic factors including marketing practices and 
infrastructure facilities need to be explored in order to obtain a better understanding of the determinants of perceptions about disease transmission risks.

\section{Appendix 1}

Meaning and construction of KAP indices

Meaning of KAP indices:

(1)Knowledge KAP: this index captures the producers' knowledge about typical bird flu symptoms.

(2)Beliefs KAP: this index measures the producers' beliefs about good practices in handling poultry and poultry products.

(3) Action KAPs: three action KAPS were created; one on handling sick birds, one on disposal of dead birds, and one on other practices.

(4) Reporting sick birds: this is constructed as index of the bad practices household denies doing.

(5)Perception KAP: this index captures how concerned the producers are about potential disease spread when there is an infection within a village.

\section{Construction of KAP indices}

Knowledge KAP: given 1 point for each of the following symptoms identified with bird flu by poultry farmer:

Sudden or unexpected death of healthy birds

Ruffled feathers

Minimal food intake

Swollen or bluish comb

Bloody diarrhea

Difficulty breathing

Reduction of ceasing of egg production

Beliefs on safe practices handling poultry and products: given 1 point for each of the following bad practices households denies doing:

Adults touch sick or dead poultry with bare hands

Children in household touch sick or dead poultry

Prepare raw poultry and other foods with the same cutting boards and utensils

Use sick or dead poultry for meal preparation

Eat poultry that is pink in the middle

Eat eggs with runny yolk

Action KAP 1: Handling sick birds: given 1 point for providing the response in parentheses to each of the following practices:

Slaughter sick fowl for food or gift (no)

Burn or destroy sick fowl (yes)

Sell sick fowl (no) 
Give antibiotics to sick fowl (yes)

Apply vaccine to sick fowl (yes)

Action KAP 2: disposal of dead birds: given 1 point for providing the response in parentheses to each of the following practices:

Consume or gift dead fowl (no)

Sell dead fowl (no)

Sell the drippings of dead fowl (no)

Burn carcasses (yes)

Bury carcasses (yes)

Leave carcasses in open (no)

Dispose carcasses in river/pond (no)

Action KAP 3: other practices: given 1 point for providing the response in parentheses to each of the following risk mitigation practices household reports doing:

Touch sick or dead poultry with bare hands (no)

Wash hands with soap and water immediately after touching sick/dead poultry (yes)

Children in household touch sick or dead poultry with bare hands or otherwise play with them (no)

Take sick or dead poultry and prepare it for a meal (no)

Prepare raw poultry and other foods with the same cutting boards and utensils without washing (no)

Wash hands with soap and water immediately after preparing poultry for cooking (yes)

Wash the cage/pen (yes)

Spray disinfectant in cage/pen (yes)

Perception on disease transmission risks:Given the equivalence of the following answers corresponding to the question: "If your neighbor told you that there are sick poultry in the village or nearby (while your birds are still healthy) how likely do you think it would be for your birds to get sick?"

Completely or very likely $=4$ (high risk)

Somewhat likely $=3$ (moderate risk)

Somewhat unlikely $=2$ (low risk)

Completely or very unlikely $=1$ (no risk)

Reporting KAP: given 1 point for each of the following answers:

Friend or neighbor

Village head/village staff

Local veterinary doctor

District veterinary office/agricultural agency

Agent/distributor

If contact/report (immediately/minutes/hours less than $24 \mathrm{~h}$ ) 


\section{Appendix 2}

Table 7 Biosecurity practices considered in the project

\begin{tabular}{|c|c|}
\hline Biosecurity practices & Description \\
\hline Biosecurity practices 1 & Closed door in the house all the time \\
\hline Biosecurity practices 2 & $\begin{array}{l}\text { Daily checking the poultry house for dead/or } \\
\text { sick bird }\end{array}$ \\
\hline Biosecurity practices 3 & $\begin{array}{l}\text { Keep the poultry in the cage during the disease } \\
\text { outbreak in the village }\end{array}$ \\
\hline Biosecurity practices 4 & Quarantine new purchased poultry \\
\hline Biosecurity practices 5 & Check the symptoms of diseases before purchase \\
\hline Biosecurity practices 6 & $\begin{array}{l}\text { Monitor interaction/contact between yours and } \\
\text { neighbors' poultry }\end{array}$ \\
\hline Biosecurity practices 7 & $\begin{array}{l}\text { Monitor interaction/contact between yours and } \\
\text { wild poultry }\end{array}$ \\
\hline Biosecurity practices 8 & $\begin{array}{l}\text { All visitors visiting the hours or livestock farm are } \\
\text { required to clean with disinfectant (go through } \\
\text { foot bath) }\end{array}$ \\
\hline Biosecurity practices 9 & $\begin{array}{l}\text { All visitors visiting the house or livestock farm are } \\
\text { required to change clothes/slippers }\end{array}$ \\
\hline Biosecurity practices 10 & Frequent cleaning of floor and cages from feces \\
\hline Biosecurity practices 11 & Operate an all-in-all-out policy for each batch/cycle \\
\hline
\end{tabular}

Source: Field Survey, 2014

Competing interests

The author declares that he has no competing interests.

Received: 22 May 2015 Accepted: 2 December 2016

Published online: 16 December 2016

\section{References}

Aitchison J, Silvey SD (1957) The generalization of probit analysis to the case of multiple responses. Biometrika 44:131-140 Ameji ON, Abdu PA, Sa'idu L, Kabir J, Assam A (2012) Awareness, knowledge, readiness to report outbreak and biosecurity practices towards highly pathogenic avian influenza in Kogi State, Nigeria. Int J Poult Sci 11(1):11-15 Avian Influenza Controlled Project (ACIP) (2014) Avian Influenza Prevention Strategies in Nigeria. Published by National Animal Disease Control Commission Nigeria

Brant R (1990) Assessing proportionality in the proportional odds model for ordinal logistic regression. Biometrics 46: $1171-1178$

Di Giuseppe G, Abbate R, Albano L, Marinelli P, Angelillo IF (2008) A survey of knowledge, attitudes and practices towards avian influenza in an adult population of Italy. BMC Infect Dis 8:36

Fielding R, Lam WWT, Ho EYY, Lam TH, Hedly AJ, Leung GM (2005) Avian influenza risk perception, Hong Kong. Emerg Infect Dis 11(5):677-682

Green W (2003) Econometric analysis, 6th edn. Macmillan, New York

Huang CL (1993) Simultaneous equation model for estimating consumer risk perceptions, attitudes, and willingness to pay for residue-free produce. J Consum Aff. 27(2):377-396

Imai T, Takahashi K, Hoshuyama T, Hasegawa N, Lim M, Koh D (2005) SARS risk perceptions in healthcare workers, Japan. Emerg Infect Dis 11(3):404-410

Jeong J, Kang HM, Lee EK, Song BM, Kwon YK, Kim HR et al. (2014) Highly pathogenic avian influenza virus (H5N8) in domestic poultry and its relationship with migratory birds in South Korea during 2014. Vet Microbiol 173(3-4):249-57

Jolly CM, Bayarda B, Awuahb RT, Fialor SC, Williams JT (2009) Examining the structure of awareness and perceptions of groundnut aflatoxin among Ghanaian health and agricultural professionals and its influence on their actions. J Socio-Econ. 38:280-287

Kumar G, Popat M (2010) Farmers' perceptions, knowledge and management of aflatoxins in groundnuts (Arachis hypogaea) in India. Crop Prod 29:1534-1541

Leggat PA, Mills D, Speare R (2007) Hostellers' knowledge of transmission and prevention of avian influenza when traveling abroad. Travel Med Infect Dis 5:53-56

Leslie T, Billaud J, Mofleh J, Mustafa L, Yingst S (2008) Knowledge, attitdues, and practices regarding avian influenza (H5N1), Afghanistan. Emerg Infect Dis 14(9):1459-1461

Liebenehem S, Affognon H, Waibel H (2009) Assessing the Impact of Agricultural Research on Farmers' Knowledge About African Animal Trypanosomosis: An Application of the Propensity Score Matching Approach. Paper delivered at conference GEWISOLA, Institute of Development and Agricultural Economics, Kiel

Ly S, Van Kerkhove MD, Holl D, Froehlich Y, Vong S (2007) Interaction between humans and poultry, rural Cambodia. Emerg Infect Dis 13(1):130-132 
Mahmoodabad SSM, Barkhordari A, Nabizadeh M, Ayatollahi J (2008) The effect of health education on knowledge, attitude and practice (KAP) of high school students' towards Brucellosis in Yazd. World Appl Sci J 5(4):522-524

McCullagh P (1977) A logistic model for paired comparisons with ordered categorical data. Biometrika 64:449-453

McKelvey RD, Zavoina W (1975) A statistical model for the analysis of ordinal level dependent variables. J Math Sociol 4:103-120

Miranda A, Rabe-Hesketh S (2006) Maximum likelihood estimation of endogenous switching and sample selection models for binary, ordinal, and count variables. Stata J 6(3):285-308

National Bureau of Statistics (NBS) (2014) Integrated Agriculture Survey 2013., Published by Federal Ministry of National Planning Nigeria

Narrod, C., Tiongco M, Kobayashi M, Scott R, Saak A, Nuryartono N (2010). Evaluating Risk Management Options to Reduce the Risk of HPAl for Indonesia's Poor Poultry Producers. Draft Report for HPAI DfID Project. IFPRI, Washington, D.C

Negro-Calduch E, Elfadaly S, Tibbo M, Ankers P, Bailey E (2013) Assessment of biosecurity practices of small-scale broiler producers in central Egypt. Prev Vet Med 110(2):253-62

Obi TU, Olubukola A, Maina GA (2009) Pro-poor HPAl risk reduction strategies in Nigeria: a background paper strategies for the prevention of introduction, surveillance networking and contingency plan for HPAl emergency. Report of expert committee on control of HPAl, December 2005

Okpukpara B (2015) Effects of price and non-price factors on the use of credit in poultry farming communities in Nigeria, Nigeria FAMAN Journal. 18(2):23-30

Olsen SJ, Laosiritaworn Y, Pattanasin S, Prapasiri P, Dowell SF (2005) Poultry-handling practices during avian influenza outbreak, Thailand. Emerg Infect Dis 11(10):1601-1603

StataCorp. 2009. Stata base reference manual release 11. Stata Press, 4905 Lakeway Drive, College Station, Texas 77845

Suphunnakul P, Maton T (2009) Community participation as a key element in prevention and control of avian influenza in Song Phi Nong District, Suphan Buri Province. J Public Health 39(1):61-73

Tiongco Marites, Clare Narrod, Rosemarie Scott, Mimako Kobayashi, and John Omiti (2012) Understanding knowledge, attitude, perceptions, and practices for HPAl risks and management options among Kenyan poultry producers Health and Animal Agriculture in Developing Countries, 281-305. Food and Agriculture Organization

UNDP (2007) Human Development Report., http://hdrstats.undp.org/countries/data_sheets/cty_ds_NGA.html

UNICEF-Georgia (2007) Study of knowledge, attitudes, practices, and behaviors to inform the avian influenza prevention and containment communication strategy in georgia. United Nations International Children's Emergency Fund, Georgia, p 201

UNICEF-Myanmar (2006) Knowledge-attitudes-practices (KAP) study on poultry rearing and other practices pertaining to avian influenza. United Nations International Children's Emergency Fund, Myanmar, p 65

Wilde J (2000) Identification of multiple equation probit models with endogenous dummy regressors. Econ Lett 69 309-312

Xiang N, Shi Y, Wu J, Zhang S, Ye M, Peng Z, Zhou L, Zhou H, Liao Q, Huai Y, Li L, Yu Z, Cheng X, Su W, Wu X, Ma H, Lu J, McFarland J, Yu H (2010) Knowledge, attitudes, and practices (KAP) relating to avian influenza in urban and rural areas of China. BMC Infect Dis 10(34):1-7

\section{Submit your manuscript to a SpringerOpen ${ }^{\circ}$ journal and benefit from:}

- Convenient online submission

- Rigorous peer review

- Immediate publication on acceptance

- Open access: articles freely available online

- High visibility within the field

- Retaining the copyright to your article 